\title{
Del presente a los años 60: representaciones y regulaciones sobre la vida familiar y la educación infantil en Argentina
}

\section{From the present to the 60's: representations and regulations of family life and children's education in Argentina}

\author{
Laura Beatriz CERLETTI \\ Instituto de Ciencias Antropológicas \\ Facultad de Filosofía y Letras, Universidad de Buenos Aires \\ CONICET (Consejo Nacional de Investigaciones Científicas y Técnicas, Argentina) \\ laurabcerletti@yahoo.com.ar
}

Recibido: 17 de septiembre de 2014

Aceptado: 24 de febrero de 2015

\begin{abstract}
Resumen
La atención de los niños en sus hogares ha sido objeto de cambiantes preocupaciones y acciones en distintos campos de la vida social, y en particular, en vinculación con la educación infantil. Los modos en que se representan y se buscan regular las responsabilidades y el accionar de los adultos en torno a los niños se han ido transformando como parte de procesos complejos, cuyas huellas se imbrican en la configuración de problemáticas actuales - usualmente vinculadas a representaciones fuertemente naturalizadas, que la investigación antropológica permite evidenciar y problematizar. En este artículo se analizan y se historizan algunos de estos modos de regulación de la vida familiar, según surge de nuestra investigación sobre las relaciones entre las familias y las escuelas en la Ciudad de Buenos Aires, Argentina, realizada desde un enfoque histórico-etnográfico. Específicamente, se analiza una obra paradigmática de la década de 1960: la Escuela Para Padres de Eva Giberti, tomada como analizador significativo para el estudio de esta problemática.
\end{abstract}

Palabras clave: obligaciones y responsabilidades adultas; regulaciones sobre la vida familiar; relaciones familias-escuelas; educación infantil; escuela para padres; enfoque históricoetnográfico.

\begin{abstract}
Caring of children in their homes has been an arena for changing concerns and actions in different fields of social life, particularly regarding children's education. Ways of representing adult responsibilities and obligations as well as attempts to regulate them have changed alongside complex processes. The traces of these processes can be found in the configuration of contemporary social problems, usually related to strongly naturalized representations, which anthropological research sheds light on and questions. This article analyzes and historically contextualizes some of these ways of regulating family life, as shown in our inves-
\end{abstract}


tigation about the relations between families and schools. Research took place in the City of Buenos Aires, Argentina, and followed a historic-ethnographic approach. Specifically, the article addresses a paradigmatic publication from the 1960's: the "School for Parents" by Eva Giberti, considered a meaningful analyzer for studying these issues.

Keywords: adult obligations and responsibilities; regulations of family life; families-schools relations; children's education; school for parents; historic-ethnographic approach.

Referencia normalizada: Cerletti, L.B. (2015) Del presente a los años 60: representaciones y regulaciones sobre la vida familiar y la educación infantil en Argentina, en Revista de Antropología Social 24, 349-374.

SUMARIO: 1. Introducción. 2. Tras las huellas de un proceso de reconfiguración: puntos de partida y articulaciones. 3. De la "Escuela para Padres". 3.1. La noción de niño y la centralidad de la familia. 3.2. La responsabilidad parental. 3.3. La madre y la maestra: cuestiones de género en la constitución psíquica y en la educación de los niños. 4. Palabras finales. 5. Referncias bibliográficas.

\section{Introducción}

El modo en que se atiende a los niños en el seno de sus hogares ha sido objeto de preocupaciones y acciones cambiantes a lo largo del tiempo, en distintos campos de la vida social, y en particular, para diversos sujetos e instituciones vinculados a la educación infantil. Las formas de concebir las responsabilidades adultas en torno a los niños se han ido transformando como parte de procesos complejos, atravesados por diversos conflictos y tensiones. Las huellas de estos procesos se imbrican en la configuración de múltiples situaciones y problemáticas actuales, usualmente vinculadas a representaciones fuertemente naturalizadas, que la investigación antropológica permite evidenciar y problematizar. Este artículo se centra en algunos de estos modos de regulación de la vida familiar ${ }^{1}$, según surge de nuestra investigación sobre las relaciones entre las familias y las escuelas en la Ciudad de Buenos Aires, Argentina, realizada desde un enfoque histórico-etnográfico ${ }^{2}$. El propio proceso de investi-

${ }^{1}$ Este artículo es una versión revisada, ampliada y reformulada de una ponencia presentada en las IV Jornadas Nacionales de Historia Social (La Falda, Córdoba, Argentina). Agradezco a Isabella Cosse por los comentarios enriquecedores que realizó a ese trabajo en el marco de dichas Jornadas.

${ }^{2}$ En términos teórico-metodológicos, el enfoque histórico-etnográfico desde el cual llevamos a cabo la investigación pone en primer plano tanto el desarrollo de las prácticas cotidianas como los sentidos que sus protagonistas despliegan en torno a las mismas. Asimismo, partimos de una concepción de la vida cotidiana como historia acumulada: la "vida cotidiana" está impregnada de contenidos históricos, y su análisis delimita y recupera conjuntos heterogéneos de actividades emprendidos y articulados por sujetos particulares (Ezpeleta y Rockwell, 1987; Rockwell, 2009). Entender la existencia cotidiana como historia acumulada pone en primer plano la necesidad de abordar el presente en términos historizados (Sanjek, 1991; Neufeld, 1996/1997), 
gación ${ }^{3}$ nos ha ido conduciendo hacia interrogantes que contemplan la problemática en temporalidades de mayor alcance. Específicamente, acá nos centraremos en una obra paradigmática de la década de 1960: la Escuela Para Padres (Giberti, 1968

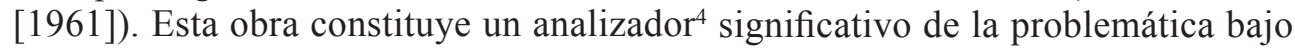
estudio, según se retoma luego.

Nuestra atención a este tema tiene una base de sustentación específica. Contemporáneamente, tanto en el contexto local como internacional, existe una abundante producción de textos, de lineamientos de políticas y de iniciativas dirigidas a indicar modos de acción a las familias de los niños en pos de garantizar su plena escolari-

desde un enfoque relacional (Achilli, 2005). Es decir, reconstruyendo analíticamente las relaciones existentes entre diversos procesos sociohistóricos y las acciones y significaciones registradas en el presente. De tal modo, se plantea al proceso de investigación como "el esfuerzo por relacionar distintas dimensiones de una problemática analizando los procesos que se generan en sus interdependencias y relaciones históricas contextuales" (Achilli, 2005: 17). También es necesario aclarar que tomamos el concepto de contexto como un "entramado de relaciones significativas, que se va construyendo conforme avanza la investigación y la escritura del texto etnográfico [...]. $\mathrm{Y}$ en este sentido decimos que el contexto es un proceso: el proceso de alumbramiento de relaciones significativas entre los fenómenos socioculturales" (Velasco y Díaz de Rada, 1997: 235).

${ }^{3}$ Se trata de un proceso que contempló distintas etapas en su desarrollo. Entre el año 1999 y 2003 nos abocamos centralmente al estudio de las representaciones sobre las familias de los alumnos identificables entre distintos docentes y personal vinculado a las escuelas (directivos, miembros del Equipo de Orientación Escolar, etc.). En esa etapa, el trabajo de campo se desarrolló en dos escuelas ubicadas en un distrito del noroeste de la Ciudad de Buenos Aires, entre los años 1999 y 2001. Luego, entre los años 2004 y 2010, se ampliaron los interrogantes de la investigación para incorporar en primer plano las prácticas cotidianas llevadas a cabo en el ámbito doméstico por los adultos con niños en edad escolar a su cargo (padres, madres, abuelas, entre otros) vinculadas a la educación y escolarización infantil y a los sentidos construidos en torno a ello. Asimismo, se observaron y analizaron las prácticas llevadas adelante por los docentes y los sentidos construidos en torno a los alumnos y sus familias, contemplando especialmente las interacciones entre los distintos adultos vinculados a la escolarización de los niños. En esta etapa, el trabajo de campo se realizó entre los años 2004 y 2006, y luego en un período durante 2008, dentro y fuera de la escuela, en un barrio (una ex villa de emergencia) de la zona sur de la Ciudad de Buenos Aires. Se trata de la zona donde más visibles se hacen las marcas de la desigualdad social dentro de la Ciudad. Allí se realizaron tanto observaciones participantes como entrevistas abiertas en profundidad en distintas instituciones barriales (capilla, centro de salud, feria semanal, etc.), así como en distintas casas, y en una escuela ubicada en el mismo. Una línea interesante de esta investigación, en términos de historización de los procesos bajo estudio, fue trabajar sobre los relatos autobiográficos de los distintos adultos entrevistados, ya que permitió visibilizar aspectos poco conocidos de los modos de acción y organización familiar en vinculación a la educación, y especialmente, generar algunas hipótesis de trabajo y nuevos interrogantes sobre los cambios y reconfiguraciones en este campo de la vida social. Por tanto, este proceso de indagación continúa en una tercer etapa en curso, a través de la realización de entrevistas en profundidad de carácter biográfico con docentes retirados y del relevamiento de fuentes documentales. Como parte de esta última etapa, cobra importancia la obra que se analiza puntualmente acá.

${ }^{4}$ Entendemos por 'analizador' a "una situación significativa con respecto a una problemática de investigación que permite estudiar en detalle factores, elementos, lógicas, actores, etc." (Althabe y Hernández, 2004: 76). 
zación ${ }^{5}$. Estas producciones ${ }^{6}$ suelen tener un marcado peso prescriptivo sobre las formas de vida familiar, dando por sobreentendidas ciertas correlaciones entre el accionar de los padres y especialmente de las madres, con los resultados de la educación y escolarización de los niños ${ }^{7}$. Recurrentemente, se insiste para que las familias generen espacios y tiempos determinados dentro del hogar para la realización de actividades escolares, que asistan a las citaciones periódicas de la escuela, supervisen y acompañen la realización de tareas en el ámbito doméstico, provean

${ }^{5}$ Concretamente, organismos internacionales como UNESCO y UNICEF se han abocado a impulsar estas recomendaciones. En este sentido es ilustrativo un documento elaborado por UNICEF en la Argentina en 2002, titulado "Las escuelas y las familias por la educación. Guía de Orientación para el Trabajo en Talleres", que hemos analizado en profundidad anteriormente (ver Cerletti, 2014). También a modo de ejemplo, se puede consultar el documento publicado por UNESCO en Chile en 2004, titulado "Participación de las familias en la educación infantil latinoamericana" (OREALC / UNESCO, 2004), que parte de "un proyecto regional que tiene como finalidad fortalecer la participación y la educación de madres y padres como principales educadores de sus hijos e hijas", y en el que se plantea que "en los últimos años la participación de las familias, de los padres y madres en la Educación ha sido tema de discusión, especialmente por tres razones: en primer lugar, por la relación encontrada, en algunas evaluaciones realizadas en la Educación Básica, entre la articulación familia y escuela y mejores aprendizajes en los niños y niñas; en segundo lugar, por el reconocimiento de las madres y padres como primeros educadores de sus hijos e hijas, demostrándose el impacto positivo que puede tener una educación temprana de calidad en el desarrollo y aprendizaje de los niños y niñas, y en tercer lugar, porque la familia aparece como un espacio privilegiado para lograr una ampliación de la cobertura de la educación de la primera infancia". Por cierto, lineamientos de este tipo son también objeto de políticas públicas desarrolladas en la Argentina y en muchos otros países (Nogueira, 2011; Hurtig y Dyrness, 2011). Desde el punto de vista de la producción de textos, vale mencionar a modo de ejemplo a Martiñá (2003), un libro de amplia difusión en el ámbito local, que resulta representativo entre muchos otros del mismo sesgo. Más allá del ámbito local, las producciones orientadas hacia el "parent involvement" son también ilustrativas de esta tendencia (ver por ejemplo Anderson y Minke, 2007).

${ }^{6}$ Además de las mencionadas en la nota anterior, otras de las referencias significativas de estas producciones en el ámbito local son los cuadernillos publicados por el Ministerio de Educación de la Nación y el Consejo Federal de Educación en grandes tiradas (más de un millón de ejemplares) para repartirlos a "las familias" de los niños (Ministerio de Educación, Ciencia y Tecnología y Consejo Federal de Educación, 2007), titulados "Familias con la escuela. Juntos para mejorar la educación" (se trata de una colección que incluye un número por cada grado escolar). También se pueden mencionar las "Jornadas Escuela, Familias y comunidad" organizadas anualmente por el mismo Ministerio desde el año 2012 (ver http://escuelayfamilia.educ.ar/). Y vale señalar, asimismo, las publicidades que el mismo Ministerio publicó en el Diario Página/12 durante el año 2012 (ver www.pagina12.com.ar), en la Televisión Pública (canal 7) y en afiches en la vía pública. En otro nivel jurisdiccional, también se pueden referenciar algunas políticas del Ministerio de Educación de la Ciudad de Buenos Aires, tales como el programa "Familias a la Escuela" (ver http://www.buenosaires.gob.ar/familiasalaescuela). Respecto a las producciones de organismos internacionales, junto con las mencionadas previamente, se pueden consultar, entre otros, los documentos producidos por UNICEF-Chile "Construyendo una alianza efectiva familias escuelas" (2007) y "Acercando las familias a la escuela" (2009). También ver "Interacción escuela-familia. Insumos para las prácticas escolares", UNESCO y Ministerio de Educación de Brasil (2012).

${ }^{7}$ Para un desarrollo en profundidad de este análisis (que por razones de espacio no se puede ampliar acá) ver Cerletti, 2014; también Santillán, 2012. 
útiles y materiales específicos, por mencionar algunas de las demandas más frecuentes $^{8}$. Al mismo tiempo, suelen deslizarse supuestos muy marcados respecto a la nuclearidad como forma "correcta" de organización familiar en pos de una "buena" socialización infantil ${ }^{9}$. Y simultáneamente, se registran también reclamos y demandas en torno a estas acciones y quejas sobre las características de las familias de los niños con toda frecuencia en las charlas con y entre docentes, según relevamos a lo largo de nuestra investigación.

No obstante, lejos de constatar estas correlaciones, la investigación en profundidad de las prácticas cotidianas muestra un escenario complejo, donde es imposible determinar apriorísticamente la correspondencia entre ciertas acciones adultas y sus efectos lineales en los niños ${ }^{10}$. Asimismo, permite evidenciar que las formas en que las familias y las escuelas se han relacionado a lo largo del tiempo han sido sumamente variadas. Y la escolarización de los niños se ha logrado a lo largo de distintas generaciones junto con esa variabilidad, a contramano de lo que dejan entrever las producciones aludidas (Cerletti, 2014).

Efectivamente, a través del propio proceso de investigación, al ahondar en el análisis de las experiencias de distintos sujetos a partir del trabajo con relatos autobiográficos y de las distintas fuentes relevadas, registramos a lo largo de las últimas décadas una reconfiguración de los modos en que se representa tanto el lugar que deben ocupar las familias respecto a la escolarización infantil como el rango de acciones prescriptas para propiciarla. En esta reconfiguración confluyen múltiples procesos. Nos enfocamos en particular en las transformaciones que tuvieron lugar en la década del 60 en nuestro contexto, ya que han dejado una impronta insoslayable para entender esta reconfiguración, y la centralidad y especificidad atribuida a las familias actualmente.

Uno de estos procesos se vincula con la extensa difusión que tuvieron las llamadas teorías "psi" "11 que dio lugar a un proceso de transformación de las concepciones sobre la infancia, y junto con ello, de la vida familiar y las responsabilidades adultas en torno a la educación de los niños. Dentro de la difusión masiva de estas teorías se encuentra lo que se dio en llamar "Escuela para Padres", una experiencia de dimensiones internacionales (Ohayon, 2000), que en la Argentina fue especial-

${ }^{8}$ Estas indicaciones han sido relevadas entre otros, en los distintos documentos mencionados en las notas 5 y 6.

${ }^{9}$ También se pide a las escuelas que generen "aperturas" hacia las familias de los niños, que busquen y estimulen su "participación" en diversas instancias de la vida escolar, que refuercen los vínculos con los padres, entre otras cuestiones que por razones de espacio no desarrollaremos acá (ver Cerletti, 2014).

${ }^{10}$ Este argumento, vinculado al reconocimiento de la capacidad de agencia de los niños, ha sido desarrollado desde distintos ángulos por diversas investigaciones. Por mencionar dos aportes que consideramos muy significativos al respecto, ver Rockwell, 2011 y Santillán, 2012. Para un desarrollo en relación a nuestro tema, ver Cerletti, 2014.

${ }^{11}$ En este proceso de reconfiguración se pueden ubicar también las huellas de procesos históricos de otros órdenes, que por razones de espacio no se abordan en este artículo. 
mente impulsada por Eva Giberti ${ }^{12}$. Esta autora publicó una extensa obra del mismo nombre, de amplia divulgación, editada por primera vez en 1961 y con numerosas reediciones hasta 1973. El objetivo de este artículo es analizar esta obra considerando las siguientes dimensiones ${ }^{13}$ : la noción de niño que presenta y la centralidad de la familia en su sano desarrollo, los modos en que se instala una determinada idea de responsabilidad parental, y el sesgo de género reconocible en el lugar que asigna a la madre y a la maestra en la constitución psíquica y en la educación de los niños. Vale aclarar que este análisis no busca realizar una comparación directa entre pasado y presente. Sin embargo, puesto en diálogo con la bibliografía específica producida en los últimos años sobre estos temas y con lo registrado en el trabajo de campo, permite ampliar el conocimiento sobre los procesos históricos que dieron lugar a estas reconfiguraciones y representaciones contemporáneas, y revisar los supuestos y sobreentendidos mencionados. Así, es también un propósito del artículo aportar argumentos en torno a la significatividad de esta obra para entender los procesos de reconfiguración aludidos.

\section{Tras las huellas de un proceso de reconfiguración: puntos de partida y articulaciones}

El análisis de la obra que analizaremos en los próximos apartados es inescindible del proceso de indagación de larga duración del que forma parte. Como venimos planteando, nuestras afirmaciones surgen de la investigación histórico-etnográfica mencionada sobre las relaciones entre las familias y las escuelas. La profundización en el estudio de esta temática se ha ido realizando en una doble dirección: documentando lo no documentado del presente (Rockwell, 2009), y documentando diferentes huellas históricas de su producción. Entre otras, es el caso de la obra en cuestión en este artículo. Por tanto, antes de avanzar en el análisis de "Escuela para Padres" en torno a las dimensiones señaladas, es importante especificar los puntos de partida que tomamos y las articulaciones conceptuales de las que este análisis forma parte. Así, una de las conclusiones centrales a la que llegamos es que, en las últimas décadas, la relación entre las familias y las escuelas se ha transformado en un "problema

${ }^{12}$ Eva Giberti es Psicóloga y Asistente Social. Además de la obra analizada acá, ha tenido una extensa y profusa producción (teórica y de intervención) en temáticas diversas tales como género, adopción, violencia de género, familia, entre otras. Actualmente, es coordinadora del Programa "Las Víctimas contra las Violencias", perteneciente al Ministerio de Justicia y Derechos Humanos de la Nación (Argentina).

${ }^{13}$ Vale mencionar que la búsqueda e interpretación de fuentes documentales, incluyendo esta obra, se realiza desde el mismo enfoque teórico metodológico ya mencionado en la nota al pie 2, en tanto permite ahondar en el análisis sociocultural de los modos en que determinadas problemáticas contemporáneas se han ido configurando a lo largo del tiempo, dejando heterogéneas huellas de distintos procesos en el presente, que la investigación de corte histórico-etnográfico va hilvanando, y así, ampliando el análisis interpretativo en temporalidades de creciente alcance (ver Rockwell, 2009; Neufeld 1996/1997). De esta forma, la indagación se orienta por la búsqueda antropológica de desnaturalizar las concepciones sociales más profundamente ancladas, dadas por obvias, en el presente. Por cierto, evidenciar su historicidad es una de las formas de demostrar la no-naturalidad de los procesos en cuestión. 
social" (en el sentido de Bourdieu y Wacquant, 1998). Se construyen y se demandan ciertas formas de "acompañamiento" y "participación" de las familias en la escolarización infantil como una suerte de condición sine qua non de la educación escolar, junto con una marcada preocupación sobre cómo son las familias de los niños, por contraste a cómo deberían ser. Se trata de cuestiones que según lo que documentamos no sucedían en los orígenes del sistema educativo argentino ni en su desarrollo durante varias décadas del siglo XX. Asimismo, la frecuencia y la conflictividad con que se alude a esta relación en la cotidianeidad social, especialmente según se registra en el contexto escolar, el aumento de publicaciones especializadas usualmente dirigidas a docentes y también muchas de corte académico, el tratamiento del tema en los medios masivos de comunicación, la creciente presencia de proyectos y programas destinados a mejorar la relación entre "familias" y "escuelas", las indicaciones dirigidas a los padres - y especialmente las madres - sobre cómo actuar y cómo llevar adelante la vida familiar para propiciar la educación de los niños, entre otras cuestiones, son indicios que evidencian este proceso de construcción de la relación como un "problema social" (Cerletti, 2014).

Por supuesto, como todo problema social, no es natural, sino que conlleva un proceso de construcción. Tomando algunas investigaciones realizadas desde el campo de la Historia de la Educación en la Argentina (Carli, 2005; Puiggrós, 1991; Finocchio, 2009; entre otros), se infiere que la relación entre las familias y las escuelas no era socialmente tematizada como una problemática relevante como lo es en la actualidad. Simultáneamente, retomamos una indagación realizada por la antropóloga Laura Santillán, que analizó publicaciones especializadas dirigidas fundamentalmente a docentes, desde finales del siglo XIX hasta cerca de mediados del $\mathrm{XX}, \mathrm{y}$ en ellas constata que no aparece la relación entre las familias y las escuelas presentada ni problematizada en los términos contemporáneos (Santillán, 2009). Sí se ubica una preocupación por que las familias cumplieran con la obligatoriedad escolar, y con la transmisión de los valores patrióticos, pero la confianza estaba puesta en las herramientas de enseñanza, con lo cual no se enfocaba la relación con las familias de los niños en los términos que se plantea hoy en día (Santillán, 2009; ver también Finocchio, 2009).

En la misma dirección, es importante señalar que en las entrevistas que realizamos con docentes y tutores de los niños ${ }^{14}$, registramos que se establece una diferencia generacional entre lo que sus padres hacían para con ellos en torno a la escolaridad, y lo que ellos hacen con sus hijos y/o esperan que los padres de sus alumnos hagan. Es decir, lo que se demanda actualmente como "acompañamiento" y "participación" no siempre formó parte de las acciones realizadas y/o valoradas por sus padres u otros adultos vinculados a ellos en el ámbito doméstico a lo largo de sus propias experiencias formativas ${ }^{15}$ (Cerletti, 2014). Según surge de esas entre-

${ }^{14}$ Ver nota al pie 3.

${ }^{15}$ También vale mencionar que en las mismas entrevistas, surgían relatos en los que se evidenciaban formas muy cambiantes y heterogéneas de organización de la vida familiar, lo cual también resultaba contrastante con las frecuentes e insistentes alusiones a la "mala constitución" de las familias de los niños y sus consecuencias negativas en la escolaridad. 
vistas, y considerando las periodizaciones realizadas por los mismos sujetos entrevistados, estos cambios generacionales se producen entre finales de la década del 50 y mediados de los 70 .

Como se dijo en la introducción, esto coincide con el período en que se divulgan ampliamente las teorías "psi", lo cual contribuyó a establecer una nueva concepción sobre la vinculación entre las experiencias tempranas de los niños producidas en el seno familiar, particularmente en relación a sus padres, y la constitución subjetiva del niño, con fuertes implicancias en el ámbito educativo (Carli, 1997; Plotkin, 2003; Donzelot, 1991). Es significativo que la difusión de estas teorías se produce en paralelo con la creación de las carreras de Psicología, Ciencias de la Educación y Psicopedagogía en la Ciudad de Buenos Aires, Argentina. Así, se dan las "condiciones de posibilidad para la vinculación entre psicoanálisis y educación" (Carli, 1997: 233). En este contexto, se generan experiencias centradas en la divulgación de estas nuevas concepciones, tales como la "Escuela para Padres" (Carli, 1997; Cosse, 2010a; Giberti, 2005; Vezzetti, 1999; Plotkin, 2003). Según la investigadora Sandra Carli, los efectos de esta divulgación sobre el campo educativo implicaron un desplazamiento hacia una "actitud psicologista", y con ello, a un nuevo posicionamiento de la escuela frente al niño. Nuestra hipótesis central de trabajo es que esto ha dejado huellas profundas, incluyendo la formación y las experiencias de los docentes. De esta forma, se expandió una concepción "vulgarizada" (Segalen, 1992) de las teorías de origen, plasmada en discursos que modelizan determinada forma de vida familiar como condición necesaria para la escolarización infantil.

Pensamos que estos procesos dieron lugar a una resignificación de la infancia, incluyendo su educación y la vida familiar. Más específicamente, coadyuvaron a una nueva distribución de responsabilidades y obligaciones adultas. Esto ha dejado una impronta profunda hasta el presente en los modos en que se representa y se prescribe tanto la relación entre las familias y las escuelas, como las construcciones sobre cómo deben ser y actuar las familias en pos de la escolaridad de los niños. Por supuesto, no se trata de procesos lineales ni de determinaciones directas, pero sí pensamos que se trata de huellas significativas. Por tanto, ameritan ser estudiadas con detenimiento para comprender la contemporaneidad de este "problema social". Así, a continuación nos detendremos en la "Escuela para Padres" en torno a las dimensiones de análisis que consideramos más significativas para atender a esta temática de estudio.

\section{De la "Escuela para Padres"}

En el período mencionado hubo diversas experiencias llamadas "Escuela para Padres", tanto en la Argentina como en muchos otros países. Por la masiva difusión que ha tenido en nuestro contexto de investigación, y las estrechas conexiones que tuvo con las de otros países, nos enfocaremos en la de Eva Giberti. Ella, junto al pediatra Florencio Escardó, organizaron las Escuelas para Padres en el Hospital de Niños, donde este último era jefe de servicio. A partir de 1957 y hasta fines de 1960, Giberti escribía una columna sobre crianza en el diario La Razón, tres veces por semana. Además, publicaba artículos en otras revistas populares y periódicos. Hacia 
fines de 1960, dirigía un programa de televisión también llamado "Escuela para Padres" (Plotkin, 2003). En 1961, en base a estos artículos y columnas compilados y editados, publicó "Escuela para Padres" (en adelante, EPP), con prólogo de Florencio Escardó; una obra de tres tomos que como dijimos, fue reeditada numerosas veces y vendió más de 150.000 ejemplares (Plotkin, 2003). Asimismo, Escardó y Giberti daban charlas, conferencias y cursos, con llegada a una audiencia amplia y variada, que eran auspiciadas por diversas organizaciones (Cosse, 2010a).

Si bien hubo otros divulgadores del psicoanálisis — que lo equiparaban, como en el caso de Giberti, con la psicología-, Plotkin considera que Escardó, y Giberti en particular, tuvieron "un papel crucial en la popularización del psicoanálisis" (Plotkin, 2003: 170). Esto se debió al lenguaje simple y sin terminología demasiado especializada, a la alusión permanente a una "familia típica", a la cautela con la que Giberti trató algunos de los temas más resistidos del psicoanálisis, tales como la sexualidad ${ }^{16}$, y a su adscripción profesional relativamente marginal dentro del mundo académico ${ }^{17}$. Al mismo tiempo, "el mensaje de Giberti llegaba con facilidad a amplios sectores porque se presentaba como científico y progresista sin parecer subversivo ni resultar intimidatorio [...]. Por otra parte, Giberti nunca cruzó el umbral de lo aceptable por la moral tradicional" (Plotkin, 2003: 173). Esto nos parece importante en tanto permite entender en términos de procesos de reconfiguración las transformaciones que analizamos. Es decir, manteniendo cuestiones previas, se van incorporando cambios relativamente novedosos, según iremos desarrollando.

Asimismo, la historiadora Isabella Cosse aporta más elementos para entender los motivos del gran alcance que tuvieron estos discursos, apuntando a dos cuestiones clave. Por un lado, el auge que tuvieron en la época los medios masivos de comunicación permitió una llegada a un número creciente y significativo de la población. En el caso de Eva Giberti, se dirigía especialmente a los sectores medios y populares. Y por otro lado, inscribió su trabajo internacionalmente al integrar la Federación Internacional de Escuelas para Padres y Educadores. De este modo, logró consolidar y legitimar más ampliamente su obra (Cosse, 2006 y 2008). Si bien en este artículo se desarrolla la particularidad del caso a nivel local, por su articulación con las transformaciones trasnacionales ocurridas en el período y las huellas que han dejado en el presente, puede resultar un analizador significativo para el estudio del fenómeno en términos más amplios.

Las dimensiones de análisis que elaboramos se construyeron a partir de una lectura crítica de los tomos escritos por Giberti, orientada por las hipótesis e interrogantes de investigación que describimos más arriba. Esto no significa de ninguna manera que cada una de estas dimensiones agote las temáticas abordables y discu-

${ }^{16}$ Sin embargo, según señala Isabella Cosse, el modo en que Giberti trató el tema de la sexualidad fue cambiando con los años, trabajándolo mucho más explícitamente en su obra de 1968 "Adolescencia y educación sexual", acorde con los cambios al respecto en la sociedad argentina y en el contexto transnacional (Cosse, 2006; 2010b). Argentina.

${ }_{17}$ Por ejemplo, nunca fue aceptada como miembro de la Asociación Psicoanalítica 
siones posibles, pero sí nos resultan significativas para seguir profundizando en el estudio de los procesos en cuestión ${ }^{18}$.

\subsection{La noción de niño y la centralidad de la familia}

Como ha sido trabajado desde otras investigaciones (ver especialmente Vezzetti, 1999; Plotkin, 2003; Cosse, 2006; 2008 y 2010a; y Rustoyburu, 2010), la noción de niño que transmite esta obra está fuertemente vinculada a la de un futuro miembro de la comunidad. Si bien enfatiza las particularidades del niño en tanto niño, resalta claramente que lo que importa atender en relación a ese niño de hoy es que se trata del hombre de mañana. En este sentido, plantea que "no se educa al niño para que viva solo, o para que viva al lado de papá y mamá: se lo educa como futuro miembro de una comunidad" (Giberti, 1968 [1961]: [tomo 1] 42).

La figura del niño presente aparece vinculada a cuestiones positivas tales como su deseo de indagar, de explorar, etc.; y transmite cierta imagen de un niño sin mal$d a d$. En esta noción de niño no se puede escindir la idea del niño de hoy como hombre de mañana, a la vez que como un ser presente que porta en sí todas las posibilidades - positivas y negativas - para desarrollar ese hombre ${ }^{19}$. En tanto tal, tiene particularidades que resultarían desconocidas en el contexto social de producción de esta obra. Difundirlas, para esta autora, es de vital importancia. En este sentido, resalta las posibilidades futuras englobadas en ese niño presente: "Tener fe en las potencialidades del niño, fe en el niño como ser potencial y perfectible, es uno de los pilares de la actual educación" (Giberti, 1968 [1961]: [tomo 1] 44). Ciertamente, conceptualizar a los niños como hombres del mañana, y por tanto, con un importante peso en la delineación de la sociedad futura, no constituía algo muy novedoso. Sin embargo, el énfasis puesto en la particularidad psicológica de los niños comienza a mostrar una diferencia significativa respecto a las nociones que predominaban en las décadas precedentes, según retomaremos luego.

Esta vinculación del niño presente con el hombre futuro, para la autora de la EPP conlleva una preocupación central por su cuidado. Pero no se trata ya de un cuidado del cuerpo, sino de la psiquis del niño — es decir, el cuidado de su presente por su efecto como hombre futuro. En este sentido, discute explícitamente con las tendencias de la época a preocuparse por la salud física del niño. La influencia hegemónica del higienismo en las décadas anteriores, si bien también conectaba una inquietud

${ }^{18}$ Por cierto, la investigadora Isabella Cosse ha profundizado el análisis de la Escuela para Padres de Eva Giberti enfatizando otros aspectos sumamente significativos, tales como su articulación con los cambios culturales que tuvieron lugar en ese período histórico respecto al modelo de familia doméstico, a las transformaciones y alcances del nuevo modelo de crianza -inspirado por las teorías "psi" - y su difusión en los medios masivos de comunicación —analizando también el creciente consumo de revistas-, las apropiaciones y resistencias de los padres respecto a este nuevo paradigma, entre otras cuestiones (Cosse, 2006; 2008; 2010a y 2010b). Por razones de espacio, en este artículo nos centramos en las dimensiones señaladas, por su relevancia respecto a la problemática bajo estudio y las hipótesis propuestas.

${ }^{19}$ Usamos la palabra "hombre" en masculino - como genérico de ser humano- siguiendo la modalidad de enunciación de la autora de EPP y su contexto de producción. 
por los niños en relación a la sociedad futura ${ }^{20}$, ubicaba el eje de la preocupación en la prevención de la enfermedad y en la preservación de su bienestar físico (Rodríguez Anca, 2004). Como señala la investigadora Silvana Darré, durante la década de 1950 se produce un desplazamiento en los dispositivos pedagógicos dirigidos a las madres, corriendo el eje de intervención del peligro de muerte infantil hacia el "ámbito psíquico, a la felicidad infantil, a la neurosis y a la conflictiva interior" (Darré, 2013: 194). Claramente, la EPP de Eva Giberti se ubica en este último tipo de dispositivos.

Por ello, introduce los conocimientos sobre la salud mental del niño indicando que los padres no saben cómo ser padres. Y de ahí, la importancia del conocimiento experto y la creación y divulgación de una "Escuela para Padres"21: "La paternidad y la maternidad no admiten el error ni la improvisación, porque llevan de la mano la vida del hombre que empieza a crecer" (Giberti, 1968 [1961]: [tomo 1] 18). Les aconseja enfáticamente a los padres no escuchar a las abuelas, no guiarse por lo que les transmitieran en su entorno y lo que circula de generación en generación, y sí escuchar y consultar a los expertos, evitando repetir "el modo con que fue criado por sus padres, lo que si alguna vez puede estar bien, la mayoría de ellas está mal" (Giberti, 1968 [1961]: [tomo 1] 30).

Nos interesa señalar que en esta obra, a la luz de las anécdotas y relatos de experiencias con que encabeza cada apartado de los distintos tomos y su interpretación, existe una linealidad entre la acción adulta, especialmente de los padres, y el resultado que esta acción produce en el niño. Se ubica así una suerte de relación de acción y reacción. Es decir, si bien el énfasis central está puesto en entender la particularidad del niño y su psiquis, se trata de un niño que responde sin mayores mediaciones a las acciones de los adultos. Se puede observar que no hay casi indicios de un proceso de apropiación en la constitución subjetiva del niño en estos relatos, cuestión que sigue teniendo aún una gran vigencia como supuesto en muchas de las producciones que de hecho hegemonizan hoy el tema familias y escuelas ${ }^{22}$, retomando las discusiones que mencionamos en los apartados anteriores. En las asociaciones lineales entre acciones adultas y reacciones infantiles, queda sin lugar la capacidad de agencia de los niños (Cerletti, 2014). Vale aclarar que este análisis, que pone en juego discusiones que no se habían desarrollado aún en la década del 60 , e incorpora conceptualizaciones que por cierto no eran problematizadas en aquel momento, no busca de ningún modo producir una interpretación extemporánea, sino arrojar luz sobre las formas actuales de ese modo de conceptualizar a los niños, por las implicancias en la problemática trabajada. Efectivamente, en los discursos hegemónicos contemporáneos que mencionamos en los apartados anteriores, abundan las referencias a las acciones parentales que garantizarían per se la plena socialización

${ }^{20}$ En este sentido, es también importante mencionar la impronta de la eugenesia y de la preocupación por la "degeneración" en las décadas anteriores a nuestro período de estudio (ver Nari, 2004).

${ }^{21}$ Años después, la misma Eva Giberti revisa la idea de "escuela" de la EPP (ver Giberti, $\mathrm{s} / \mathrm{f})$.

${ }^{22}$ Ver las notas al pie número 5 y 6 , más arriba. 
de los niños. Y con ello su éxito educativo y escolar. Asimismo, en las entrevistas y observaciones que realizamos en las distintas etapas del trabajo de campo, registramos con toda frecuencia entre los docentes explicaciones que ubican en las "fallas" o "faltas" de los padres los problemas en los resultados escolares infantiles. En esas explicaciones, por cierto, muchas veces no median otros motivos más que las consecuencias "psicológicas" que tales "fallas" tienen en los niños.

Así, en la EPP los padres aparecen como determinantes del futuro de los niños. Reforzando una noción nuclear de familia, propia de las concepciones de sentido común y de mucha de la producción teórica de la época, esta vinculación del niño con los padres remite a la idea e importancia de la familia. En este sentido, la autora plantea que "vale la pena pensar si no será necesario dedicar mucha atención a la dinámica familiar desde el momento en que cada vez se demuestra con mayor fuerza y evidencia su preponderancia y proyección en la existencia de los hombres" (Giberti, 1968 [1961]: [tomo 1] 99). Esta atención no sólo se vincula con la salud psíquica actual del niño - la higiene mental, en sus términos ${ }^{23}$-, sino también, de acuerdo con la noción de niño presentada, sería central para la "sana convivencia común" (ídem). Al respecto, retoma algunas discusiones dentro de "distintos enfoques de la gran escuela psicoanalítica [...] en estos últimos diez años, un grupo de estudiosos advierte que hay algo más que las experiencias infantiles como determinantes del trastorno mental: la relación entre el individuo y la sociedad-familia" (Giberti, 1968 [1961]: [tomo 1] 101). En esta dirección, considera a la familia como "laboratorio de ensayo para la vida futura" (ídem). Abunda a lo largo de toda la obra en las condiciones de vida familiar que se requerirían para asegurar la salud mental del niño, que garantizarían el "hombre feliz". Así, cita a Bertrand Russell,

'La seguridad de los niños — concluye Russell— está basada en el afecto y en la rutina'. [Y agrega Giberti:] Y se entiende por rutina la sosegada secuencia de hábitos regulares y metódicos que interpretando, no deformando, las tendencias infantiles, las condiciona para una fructífera convivencia (Giberti, 1968 [1961]: [tomo 1] 54).

Por cierto, no es menor la insistencia de la autora en contra del castigo y la amenaza a los niños, ya que ambos se contraponen "al amor y al trabajo creador" (Giberti, 1968 [1961]: [tomo 1] 58). En el mismo sentido, critica la "falsa disciplina familiar", que no dejaría lugar a los sentimientos (al afecto y sus manifestaciones), como causante de un "hombre inadaptado, la agresividad y la susceptibilidad son formas de la inmadurez del hombre como persona" (Giberti, 1968 [1961]: [tomo 1] 64).

Como mucha de la bibliografía especializada ha evidenciado (Donzelot, 1991; Nari, 2004; Darré, 2013; entre otros), desde las décadas anteriores, la familia era una destinataria central de diversos discursos y dispositivos dirigidos a regular las acciones de sus miembros en torno al cuidado infantil, especialmente en vinculación

${ }^{23}$ Es interesante notar que en el uso de la categoría "higiene mental" que hace a lo largo de toda la obra, se observa una continuidad significativa con las tendencias de las décadas anteriores, signadas por las preocupaciones del higienismo, junto con la incorporación de aquello que implicaba la relativa novedad de su trabajo: el énfasis por la psiquis del niño. 
a las ideas sobre la sociedad futura. En este sentido, se puede observar una relativa continuidad entre la EPP y los planteos más frecuentes de los años previos, provenientes ya fuera de la puericultura, la pedagogía o la pediatría. Sin embargo, en el período que nos ocupa, y como se puede observar con claridad en el caso de la EPP, esta regulación pasa a requerir un saber específico sobre la "psiquis" del niño, que como dijimos más arriba, debía romper con lo transmitido de generación en generación. Hasta finales de la década de 1940 al menos, a las madres se les suponían unas capacidades "naturales" en tanto mujeres, que las habilitaba en particular para el cuidado de los niños (Nari, 2004). Como vemos, la EPP de Eva Giberti descarta de plano el supuesto de los saberes innatos de las mujeres, dados por su condición de género. Y más aún, cuestiona ampliamente los saberes recibidos como parte de su socialización. Instala entonces la necesidad de que los adultos responsables de las familias - madres y padres - aprendan de los expertos "psi", y no ya de médicos o puericultores exclusivamente.

A su vez, en la concepción de familia que presenta en esta obra, a pesar de referenciar a la "gran escuela psicoanalítica", tiene claras influencias de la concepción funcionalista ${ }^{24}$ predominante en la sociología y la antropología especialmente anglosajona de mediados del siglo $\mathrm{XX}^{25}$. Es significativo en este sentido que uno de sus autores de referencia para hablar de los "roles" y "funciones" en la familia nuclear sea Morris Zelditch, un sociólogo norteamericano quien escribió sobre este tema un capítulo del libro Family, Socialization, and Interaction Process, publicado en 1955 por T. Parsons y R. F. Bales. Esta concepción de la familia, que reforzaba la idea y el supuesto valor de la nuclearidad, incluía una distribución de género específica de los "roles y funciones". Asimismo, ha tenido una profunda influencia hasta la actualidad. En las producciones referidas a la vida familiar y su importancia para la educación y escolarización de los niños, implicó una clara tendencia a autonomizar a las familias respecto al contexto social mayor y la trama de relaciones de las que forman parte. Asimismo, tendió a soslayar o invisibilizar distintos procesos de interacción y sujetos diversos, relevantes en las prácticas locales cotidianas vinculadas a la educación de los niños. Estos supuestos se pueden ubicar en diversos discursos sobre las familias que se construyen actualmente, según mencionamos en la introducción, en distintos ámbitos vinculados a la educación. Nos referimos a la producción de académicos, a la gestión de políticas, a los medios masivos de comunicación, y desde ya, también recurrentemente a lo que registramos en las escuelas. Por cierto, estos supuestos implican un sentido fuertemente modelizado

${ }^{24}$ Como ha sido ampliamente debatido en el campo de las Ciencias Sociales, y en la Antropología en particular, el funcionalismo como enfoque teórico no da lugar a entender en profundidad los procesos de cambio, transformación y conflicto, por mencionar en pocas palabras algunas de las críticas centrales que se le han hecho.

${ }^{25}$ Plotkin (2003) plantea la influencia del culturalismo norteamericano en Giberti, lo cual se constata por ejemplo en sus frecuentes citas a Ralph Linton. Entendemos que estas influencias se combinan en su obra de modo casi indisociado. Asimismo, Cosse (2010) afirma también que Florencio Escardó (Escardó, 1955) tenía una visión funcionalista de la familia, y que las diferencias de "roles" entre marido y esposa eran constitutivas para él de la normalidad y la salud de la familia. 
y que autonomiza a "las familias" con respecto al contexto sociohistórico y sus determinantes estructurales (Cerletti, 2014). En las entrevistas con docentes y observaciones realizadas en nuestras distintas etapas de trabajo de campo, hemos registrado abundantemente alusiones a la "mala constitución familiar" por la falla en los "roles" y "funciones" parentales, evidenciando la fuerte continuidad histórica de estas conceptualizaciones ${ }^{26}$.

Finalmente, retomando los tomos de EPP, vale aclarar que la autora presenta al niño y su entorno familiar en términos que podríamos llamar genéricos, es decir, sin especificar la clase social de pertenencia, ni otras particularidades. Pero de las situaciones cotidianas que describe y los tipos de problemáticas que presenta, se deduce claramente que se trata de un niño de clase media o clase media baja, de una familia nuclear y urbana ${ }^{27}$. Como plantea Cosse (2010b), serían familias que podían permitirse pensar en esa dimensión de la crianza, y no de los problemas más elementales de la supervivencia, como era el caso de numerosas familias de los sectores populares. Más aún, la investigadora Silvana Darré plantea que justamente el énfasis de la EPP en ir más allá de la salud física de los niños sólo era posible dadas las mejores condiciones de vida de amplios sectores de la población alcanzadas a mediados del siglo XX, por cuanto la supervivencia infantil habría dejado de ser para entonces una preocupación central para un número mucho mayor de personas que en décadas anteriores (Darré, 2013).

\subsection{La responsabilidad parental}

Esta concepción del niño y la familia llevan indisociablemente de la mano la cuestión de la responsabilidad parental ${ }^{28}$. La misma autora plantea sobre la EPP que "la eficacia de estas páginas y el esfuerzo que significan [...] mucho más que enseñar, busca despertar el sentido de la responsabilidad" (Giberti, 1968 [1961]: [tomo 1] 30). Y más claro aún, plantea que "no se trata de cómo son los padres, sino de cómo deben ser" (Giberti, 1968 [1961]: [tomo 1] 68, resaltado propio).

Los procesos de construcción y regulación de la responsabilidad parental y las obligaciones adultas en torno a los niños, son una de las preocupaciones centrales de investigación que orientan nuestro proceso de indagación, así como de otras producciones afines con las que nuestro trabajo se retroalimenta (ver Santillán, 2012; Santillán y Cerletti, 2011; entre otros). Como se planteó en los párrafos anteriores,

${ }^{26}$ Es importante mencionar que junto con este tipo de alusiones a las familias de los niños, registramos también muchos sujetos que expresaban nociones más complejas respecto a la vida familiar y las relaciones entre padres e hijos. Sin embargo, nos ha resultado llamativa la frecuente presencia de los supuestos señalados más arriba.

${ }^{27}$ También la influencia teórica norteamericana puede tener peso en esto (ver Cosse, 2010). Al respecto, ver también Rustoyburu (2010).

${ }^{28}$ Hugo Vezzetti afirma que "tanto la centralidad de la infancia como la apelación a la responsabilidad de los padres sobre la salud psíquica y la educación moral de los niños constituían tópicos centrales de la tradición médica higienista; en ese terreno no se ofrecía nada nuevo. En todo caso, si la expansión del psicoanálisis en la cultura modificaba algo (aunque sin cancelar) las representaciones sociales sobre la salud de la infancia, lo hacía alterando la trama de significaciones que permitían pensar la relación entre el niño y el adulto" (Vezzetti, 1999: 179). 
en la EPP el presente de lo que hagan los padres para con ese niño determina su futuro como hombre, tanto en términos de su salud mental, como de su felicidad, de su inclusión en la vida social, etc. En este sentido, el hogar, cobra un lugar central en el campo de la salud mental, "como centro coordinador de las formas de la higiene mental, no es porque sea el único, sino porque es el más accesible y aquel donde los niños encuentran su ejemplo y del cual adquieren los hábitos esenciales para la convivencia" (Giberti, 1968 [1961]: [tomo 1] 38). Por tanto, si bien da lugar a la existencia de otros espacios vinculados con la "higiene mental", esta primacía del hogar y de las acciones de los padres, ponen en primer plano sus obligaciones y responsabilidades. Plantea Giberti que

Ser padre y ser madre tiene que ser una obligación inexcusable, pero libremente aceptada, y los conflictos o desacuerdos entre los cónyuges no deben repercutir nunca en el ánimo de los hijos. Un gran psicólogo contemporáneo decía con agudeza: 'No hay niños neuróticos; hay hijos de padres neuróticos', lo que pone la higiene mental como la obligación primera de quienes se animen a construir una familia (Giberti, 1968 [1961]: [tomo 1] 52-53).

No sólo serán las indicaciones en torno a cómo conducir algunas cuestiones de pareja, si no a una muy amplia gama de acciones llevadas a cabo en el ámbito doméstico, especialmente por las madres, las que irán definiendo este campo de responsabilidades y de "obligación primera", independientemente de la situación particular de los padres.

Un recurso frecuente que utiliza para plantear las obligaciones paternas es la comparación con otras "profesiones":

Más que caricias el niño necesita moverse en una atmósfera cariñosa, en un clima de seguridad afectiva. Es evidente que ello no es fácil, que los padres son también seres humanos con altibajos de carácter, sus resaltos de humor, sus contrariedades y problemas, pero también es cierto que "son padres" y tienen la obligación de cumplir con las reglas del oficio; nadie toleraría que un actor recitase mal su papel porque esa noche se ha peleado con su suegra; su oficio de actor está por encima de sus problemas personales; en buen parte el ejemplo se aplica a los padres; deben conducirse como padres y no como seres singulares, por lo menos mientras estén frente a sus hijos (Giberti, 1968 [1961]: [tomo 1] 66).

Esta comparación con un actor recitando su papel nos resulta también significativa a la luz de las nociones de "rol" de claro corte funcionalista, y de la "función" que deben cumplir los padres más allá de la singularidad de sus experiencias, vistas así como asuntos escindibles.

Asimismo, la cuestión de la responsabilidad en torno a los niños, define de alguna manera el lugar de todos los adultos como padres, planteando que

Desde el punto de vista moral somos un poco los padres de todos los chicos del mundo [...] No tenemos (y no debemos) que esperar a ser padres para ejercer nuestra paternidad o nuestra maternidad. [...] Los adultos dejan huellas indelebles en los pequeños que toman contacto con ellos con mucha más frecuencia de lo que se 
imaginan. Por eso es bueno que nos dispongamos, como ejercicio moral, a querer a todos los chicos [...] si pensamos con corrección que está frente a nosotros un hijo que desea querernos, admirarnos e imitarnos (Giberti, 1968 [1961]: [tomo 1] 51-52).

Esta ampliación de las responsabilidades adultas frente a los niños es sugerente, ya que, si bien abre posibilidades más amplias de definición de la responsabilidad frente a los niños - más allá de "ser padres"-, esta apertura se hace en términos de maternidad y paternidad. O sea, de todos los adultos de ser "un poco los padres de todos los chicos".

Por tanto, el adulto es padre/madre, y su responsabilidad parental no sólo se amplía, sino que se prioriza a cualquier otra dimensión posible de su vida. Es decir, debe realizar el esfuerzo que sea necesario para anteponer esta responsabilidad, incluyendo las nuevas acciones y predisposiciones que demanda. Cualquiera fueran las condiciones en que esté, no le deben llegar al niño los conflictos, dificultades, diferencias. Como ha trabajado la investigadora Isabella Cosse (2010a y b), el nuevo paradigma de crianza que se difunde con la EPP complejiza la tarea de los padres, de la madre particularmente, que cobra a su vez una importancia mayor en relación al desarrollo del niño. Si bien esta obra sostiene una continuidad con las tendencias anteriores dada por la apelación a la responsabilidad de los padres en el cuidado infantil, introduce una nueva forma de correlacionar la acción y la responsabilidad adulta con el pleno desarrollo de los niños. Así, los peligros que incluían las malas prácticas de parentalidad para el discurso médico higienista estaban delimitados a un conjunto amplio pero relativamente finito de preocupaciones, según mencionamos más arriba (ver Nari, 2004; Rodríguez Anca, 2004, entre otros). Sin embargo, con la EPP los peligros y riesgos de malas prácticas parentales - y más concretamente, maternales - se expanden de modo indefinido y sin límites (Darré, 2013), y están en la base de todas las explicaciones de los problemas infantiles.

En relación a la educación y escolarización de los niños, esta ampliación de las responsabilidades parentales tiene consecuencias muy significativas. Concretamente, la EPP, junto con las demás producciones del período que dieron lugar a la llamada "psicologización" de la infancia, produce un desplazamiento de la explicación de los problemas escolares de una cuestión de rendimiento escolar hacia una que lo vincula principalmente con la armonía familiar (Carli, 1997). Siguiendo a la misma autora, se puede reconocer cómo en el sistema educativo argentino, desde sus orígenes y masificación, la legitimidad de la intervención pedagógica docente se sostenía sobre la deslegitimación de la educación familiar (Carli, 1997). Esta definición, que logró hegemonizar décadas de política educativa dirigida a la infancia, implicó la subsunción de la autoridad familiar a la del Estado educador (Carli, 2005). Por supuesto que este posicionamiento no fue tampoco el resultado de un proceso natural, y mucho menos libre de conflictos. Sin embargo, como venimos planteando, la amplia divulgación de las teorías "psi" de la que la EPP es un exponente sumamente significativo, fue dando lugar a un viraje en las representaciones sobre la relación entre los niños y las responsabilidades adultas. Si un niño físicamente 
sano tenía dificultades con su escolaridad, la explicación ya no sería de incumbencia exclusiva de la escuela, si no que la mirada pasa a estar puesta en la relación del niño con sus padres, en la constitución del hogar, en el correcto cumplimiento de los "roles y funciones" parentales.

Nuevamente en este sentido nos parece importante señalar la profundidad de las huellas que estos discursos han dejado en el presente. Por supuesto no nos referimos a una influencia lineal y transparente, pero sí pensamos que han tenido lugar procesos complejos de apropiación de estos nuevos paradigmas de crianza, que llegaron con particular peso al ámbito educativo. Y dentro de este último, que por su propia historia y tradiciones es propicio a las afirmaciones prescriptivas, se ha configurado como una suerte de representación social fuertemente anclada y muy escasamente discutida, que asume esta centralidad indiscutible de la responsabilidad parental. Ésta se sostiene frente a otras formas posibles de definir la responsabilidad adulta en torno a los niños. Asimismo, estos hábitos, valores y conductas de los padres serían determinantes en la socialización de los niños y operarían como condiciones previas y necesarias para la escolarización, más allá de los procesos de apropiación de los mismos niños. Por cierto, esto incluye un fuerte sesgo de género en torno a las obligaciones de las madres y las mujeres, según ampliaremos a continuación.

\subsection{La madre y la maestra: cuestiones de género en la constitución psíquica y en la educación de los niños}

Como han puesto en evidencia los trabajos de Cosse (2010a), Rustoyburu (2010) y Darré (2013), el paradigma de crianza difundido por Giberti en la EPP asumía una clara división de género en el cuidado de los niños y en el hogar ${ }^{29}$, en consonancia con diversas producciones de la época, donde la madre tenía un lugar central para la "higiene mental" de la familia y el niño. Y como dijimos, por lo tanto, en el hombre futuro ${ }^{30}$. Así, no solo la distribución de tareas y responsabilidades domésticas entre hombres y mujeres continúan teniendo un fuerte sesgo de género, sino también la responsabilidad por la salud mental de los hombres. Por mencionar un ejemplo, son las faltas de cariño de una madre las que explican los problemas de carácter de un hombre adulto. Concluye Giberti en ese caso: "La figura materna de estos seres está frustrada por el desamor, que es el peor de los agravios a la niñez" (Giberti, 1968 [1961]: [tomo 1] 64). Más concretamente, para advertir sobre el desarrollo de la inteligencia a través del afecto, la autora plantea que "la tutela afectiva que ejerce la madre está señalando los caminos futuros del hombre" (Giberti, 1968 [1961]: [tomo 1] 73). Nos

${ }^{29}$ Como apunta Cosse, las nuevas ideas de Giberti estuvieron atravesadas por contradicciones; "la maternidad fue reafirmada desde un ángulo psicológico y fue el límite de las impugnaciones a los mandatos domésticos. En cambio [...], la nueva paternidad, en última instancia, contrariaba la división de género al requerir de los padres tareas concebidas como "femeninas" - el cuidado y el mayor tiempo dedicado a los hijos [...]. En cualquier caso, las madres y los padres no siempre se plegaron a las ideas de los expertos. Las rechazaron, las discutieron y las resignificaron" (Cosse, 2010a: 161-162). Respecto a los modos en que los padres y madres se vincularon con estas ideas, ver Cosse (2010a y 2010b).

${ }^{30}$ La misma Eva Giberti ha realizado posteriormente su autocrítica al respecto (Cosse, 2010a; Giberti, 2005). 
interesa remarcar que no solamente enfatiza la importancia del amor al niño, sino la traducción que hace en acciones concretas de la madre, que garantizarían que ese amor esté bien dado, y por lo tanto, que el niño "transite el camino de la maduración humana" (Giberti, 1968 [1961]: [tomo 1] 72), como adulto pleno. "El amor materno es algo más que lo que se creyó hasta hoy: es una garantía de vida o muerte para el niño que acaba de nacer" (Giberti, 1968 [1961]: [tomo 1] 75). Como plantea Rustoyburu, estos mandatos y presupuestos en torno a la mujer (como madre) constituían un ideal más que difícil de alcanzar, lo que permite entender la muy frecuente presencia de las mujeres en estos discursos como "patógenas" (Rustoyburu, 2010).

Nos interesa destacar que si bien en la EPP los sujetos a los que se dirige en principio Giberti son principalmente (pero no únicamente) los padres, y la responsabilidad indelegable que plantea es de los padres, esa responsabilidad se concretiza en obligaciones específicas que son de las madres. Lo mismo sucede con la descripción de las acciones cotidianas vinculadas al cuidado infantil, a las situaciones "patógenas", etc. Este doble juego entre los padres como responsables en abstracto y las madres como responsables en concreto, ha probablemente también dejado huellas significativas en la contemporaneidad. Como ya dijimos, y advirtiendo contra las extrapolaciones, interesa traer algo que hemos registrado con recurrencia en el trabajo de campo descripto anteriormente, a los efectos de seguir pensando e interrogándonos sobre estos procesos. Según hemos sintetizado en otro lugar, en base a nuestros registros de observaciones y entrevistas tanto dentro como fuera de las escuelas, concluimos que:

Si el padre colabora en la "socialización" y en la escolarización, se valora, pero si no lo hace no se suelen indicar consecuencias graves. En cambio si la madre no lo hace se condena fuertemente: en el trabajo en escuelas vimos que se consideraba causante de "problemas" escolares para los niños, en el trabajo con "mamás" por fuera de las escuelas vimos cómo se asume esta responsabilidad como fundamental para ellas mismas. Nos preguntamos si esto de alguna manera implicaría que para los hombres estuviera la opción de ocuparse de esas cosas o no, pero para las mujeres no fuera una opción, es una obligación que no se cuestiona. De ahí la idea de que se construye como una responsabilidad femenina en última instancia, aún cuando muchas mujeres trabajan, y aún cuando muchas familias tienen formas organizativas menos tradicionales —en el sentido de las "funciones" femeninas y masculinas-: en el nivel de las representaciones el lugar de "las madres" seguiría siendo el de la responsabilidad por la socialización, y el de la culpabilización ante los problemas (Cerletti, 2010: 151-152).

A su vez, si bien como dijimos los destinatarios centrales de EPP son los padres de los niños, con esta especificidad de la madre, también dedica una amplia parte del tercer tomo a la escuela. Parte desde una crítica a los maestros y al mismo sistema educativo por el desconocimiento de la psiquis del niño, y se dirige en concreto a los docentes como interlocutores. Plantea que:

A pesar de las recomendaciones, de la información científica, de la divulgación, la evidencia diaria nos pone frente a la inercia educativa en este sentido: pueden más 
los maestros tradicionalistas, aferrados a sus principios antiguos, demostradamente perniciosos, que las generaciones nuevas, conocedoras de los mecanismos psicológicos de la infancia (Giberti, 1968 [1961]: [tomo 3] 10).

De esta forma, las numerosas páginas que escribe apelando a los maestros se orientan por su preocupación por la divulgación de los conocimientos de la psicología, y especialmente de la psicología del niño, para que tengan una llegada más clara y profunda a la escuela, ya que entiende que esos conocimientos están en fuerte contraste con "la enseñanza tradicional". Simultáneamente, alude a algunos procesos de modificación en los programas educativos, pero argumenta que la clave de las modificaciones está en quienes los ejecutan, "quienes los viven" (Giberti, 1968 [1961]: [tomo 3] 9). Con una modalidad similar a la que utiliza para interpelar a los padres, aparece con centralidad la figura del maestro en las modificaciones de las acciones para con los niños: "Se modifican los programas, pero no la esencia de la educación, porque la esencia la dan los maestros, no los libros ni las disposiciones superiores" (Giberti, 1968 [1961]: [tomo 3] 11). Para la autora, esta renovación de la educación requiere el conocimiento de la perspectiva sobre el niño que difunde con la EPP:

Si bien es cierto que se impone renovar la enseñanza tradicional, siempre que esa renovación haya surgido del asesoramiento psicopedagógico y el conocimiento de la realidad intelectual de nuestros chicos, también es verdad que la escuela no es sólo un lugar donde se aprende a leer, escribir, decir poesías y copiar yesos. También se inicia el chico en la disciplina, el orden, la prolijidad, el compañerismo; por eso lo que interesa desde ese aspecto es la forma en que se desarrolla esa experiencia (Giberti, 1968 [1961]: [tomo 3] 9).

Consideramos que estos planteos deben ser leídos a la luz el esfuerzo instituyente que estaban haciendo con la EPP por difundir su concepción de qué es un niño. Esto aparecía no sólo en los tomos, sino también en todas sus variantes: en el hospital, en el consultorio, en las publicaciones periódicas, etc. Ese esfuerzo, que estaba destinado principalmente a educar a los padres en su paternidad a la luz de este conocimiento de la psicología de los niños, al dedicarse específicamente a la escolarización, incorpora claramente a los maestros como destinatarios. Es decir, este paradigma sobre la psicología infantil, la crianza y la educación de los niños, irradia hacia los adultos vistos como más directamente ligados a la cotidianeidad de los niños.

Centrando nuestra atención en los sujetos a los que se dirige en los tomos de la EPP, nos resulta llamativa una similitud en el modo en que se refiere a los padres y a los educadores. Si bien el sujeto adulto genérico son los maestros, las apelaciones específicas en las indicaciones concretas, en los análisis de casos particulares, en las referencias a diversas situaciones problemáticas, son a las maestras. De hecho, respecto a los maestros y la transformación de la escuela, plantea:

Lo corriente es que en estos temas se repitan las inflexibilidades de años anteriores, sin admitir que junto con la necesidad de cambios teóricos y prácticos en la 
enseñanza se deben renovar el estilo de la escuela y la convivencia dentro de ella. No es menor la responsabilidad de las maestras (Giberti, 1968 [1961]: [tomo 3] 9, resaltado propio).

Vale aclarar que si bien la absoluta mayoría de mujeres es una constante en el sistema educativo argentino, esta observación es relevante en tanto el mismo sistema ha contado también siempre con un porcentaje de hombres, y con claros mecanismos hasta finales del siglo XX para facilitar el ingreso de estos últimos a la docencia antes que las mujeres (Morgade, 1992).

Así, vemos que si bien la obra se dirige a los adultos que identifica como más vinculados a la crianza y la educación de los niños, se traduce como responsabilidades concretas de las mujeres: las madres y las maestras. Ellas son las protagonistas de los casos que presenta, las causantes de muchas situaciones problemáticas, las posibles actoras de los cambios o las soluciones, y similarmente, las encargadas de actuar e interactuar en torno a los niños en sus distintos ámbitos y en sus encuentros.

Esta distribución de responsabilidades entre madres y maestras, leída a la luz del esfuerzo instituyente que significa la EPP, resulta novedosa en términos de la repartición de acciones concretas y del modo en que pauta la necesidad de aprendizajes previos a la escuela para que ésta pueda hacer su parte. Como se dijo más arriba, hasta bien entrado el siglo XX, si bien la preocupación por la higiene había tenido un lugar destacado en diversas políticas, en términos de la educación infantil, la obligación principal y específica de las familias estaba claramente enfocada en el cumplimiento de la obligatoriedad escolar. Cobran entonces una relevancia especial las aseveraciones de Giberti sobre estos aprendizajes previos:

Hay ciertos hábitos que el niño debe llevar aprendidos a la escuela y no tienen por qué ser dejados en manos de los pedagogos, que bastante tienen ya por hacer. Si el chico no cumple en su casa con un aprendizaje de prolijidad mental [...] mal podrá colaborar en la escuela y vendrá todos los meses con notas, a pesar del aseo exterior del guardapolvo (Giberti, 1968 [1961]: [tomo 3] 46).

Se explaya asimismo en cómo y qué cosas deben aprender los chicos en el hogar. Como dijimos, para que los pedagogos sí puedan realizar su tarea, y para que el tránsito de los niños por la escolaridad no deje en ellos lesiones psicológicas, deberían tener lugar acciones específicas llevadas a cabo por las madres. Junto con esto, además, da una serie de indicaciones sobre cómo deben acercarse las madres a la escuela, en qué casos, y qué cuestiones deben dirimir entre las madres y las maestras.

Nos interesa resaltar que esta repartición de responsabilidades y obligaciones que plantea para la familia y la escuela respectivamente, particularizadas en acciones de las madres y las maestras, son presentadas como una suerte de encadenamiento causal. En los orígenes del sistema educativo argentino, la demanda hegemónica era que las familias cumplieran con la obligatoriedad escolar y apoyaran, acompañaran, el sentimiento patriótico que la escuela estaba tratando de transmitir, lo cual puede entenderse como algo a ser realizado en simultáneo entre la familia y la escuela. Pero en esta nueva distribución de responsabilidades en la enseñanza de hábitos, 
pensados como previos a la escolaridad, aparece con énfasis la idea de un orden sucesivo. La misma Giberti, citando un ejemplo de Italia, plantea que hay "escuelas piloto" donde se ensayan enseñanzas de hábitos tales como cepillarse los dientes, peinarse, entre otros, y deja abierta la posibilidad de que este tipo de enseñanzas pudieran corresponderle a la escuela. De todas formas, concluye rotundamente que como no están dadas las condiciones en nuestro país, es competencia de la familia:

Mientras la escuela no pueda insistir convenientemente en este tipo de hábitos, la familia debe vigilar cuidadosamente su desarrollo y no confundir: cuando la señorita se queja por la desprolijidad, no se refiere necesariamente al botón que falta o a la oreja que esconde lo que no debe, sino al estilo de vida que el chico descubre en la escuela y que diagnostica despreocupación familiar, o bien un deformado entendimiento de las obligaciones parentales: hacer las cosas en lugar del chico no es positivo para él, y de tal modo sólo se fomenta su haraganería o su indiferencia (Giberti, 1968 [1961]: [tomo 3] 48).

No podemos dejar de mencionar, para finalizar, que a lo largo de los años de trabajo de campo con docentes y otros sujetos vinculados a la educación y escolarización infantil, hemos registrado con una recurrencia enorme afirmaciones, quejas, demandas, sumamente llamativas por su afinidad con estos planteos.

\section{Palabras finales}

Los modos en que se representan las relaciones entre las familias y las escuelas, y en que se prescriben las acciones parentales para garantizar la plena educación infantil ${ }^{31}$, constituyen un campo fértil de indagación para evidenciar los procesos de construcción, cambiantes a lo largo del tiempo, respecto a las regulaciones sobre la vida familiar y la producción social de responsabilidades y obligaciones adultas en torno a los niños. Si bien muchos de los discursos que circulan actualmente, según se mencionaron en la introducción, parecieran indicar que se trata de formas indiscutibles en pos de la socialización de los niños - $\mathrm{y}$ en este sentido, se encuentran fuertemente naturalizadas-, la indagación en profundidad muestra que son en realidad el producto de complejos procesos de producción.

En este artículo nos propusimos analizar una obra sumamente significativa por lo influyente que ha sido en nuestra sociedad en la definición de este tipo de regulaciones. De tal modo, abordamos este estudio desde un enfoque que considera al presente como parte de una historia acumulada, de forma ecléctica, heterogénea, pero cuyas huellas son también objeto de discusión, indagación e historización. Por tanto, este trabajo se enfrenta al desafío que implica para la investigación antropológica la

${ }^{31}$ Retomando lo que planteamos al principio, recordamos sucintamente que los pedidos más recurrentes incluyen la injerencia de los padres en algunas cuestiones pedagógicas, tales como la supervisión de tareas, el seguimiento de los cuadernos o carpetas escolares, que estén al tanto de los contenidos enseñados para contribuir con explicaciones en el ámbito doméstico, etc. Se requiere también una presencia física frecuente en el edificio escolar a través de diversas convocatorias, y se demanda un amplio conjunto de acciones familiares tendientes a propiciar una "correcta" socialización infantil (Cerletti, 2014). 
historización del presente. En tal sentido, desarrollamos acá una línea en particular, en nuestra búsqueda por dar cuenta con crecientes niveles de profundidad - tanto temática como temporal — de los procesos de producción de la relación entre las familias y las escuelas como un "problema social" del presente. Por cierto, con la difusión masiva de las teorías "psi", de lo cual la EPP acá analizada es un importante exponente, se amplían a un conjunto cada vez mayor de la población ciertos supuestos que reubican la responsabilidad parental en la salud psíquica del niño. Si bien no hay mucho de nuevo en la existencia de toda una serie de saberes, discursos y dispositivos dirigidos a que los padres y las madres, especialmente, cumplieran con sus responsabilidades y obligaciones respecto a los niños, sí se va instalando una nueva concepción respecto a cuáles deberían ser esas responsabilidades. Según surge de nuestro análisis, la importancia del amor materno y los límites, la evitación de que los conflictos adultos lleguen a los niños, la insistencia en la condena a los castigos físicos, el reparto de roles al interior de la pareja en términos de "funciones" psicológicas, y no ya restringidas a la provisión y el cuidado dado por hombres y mujeres respectivamente, son algunos de los tópicos más significativos para nuestra temática de estudio, que se empiezan a consolidar con la divulgación de estas teorías.

Por cierto, la EPP de Eva Giberti ha tenido una trascendencia muy especial, según ha sido explicado de diversas maneras por distintos autores (Cosse, 2006, 2010a y 2010b; Darré, 2013; Plotkin; 2003; Vezzetti, 1999), pero también según hemos relevado en nuestro trabajo de campo. Efectivamente en nuestras entrevistas, entre otras cuestiones, hemos registrado que distintos sujetos - particularmente docentes - contaban con los tomos en sus casas, recordaban programas de televisión o radiales, o leían sus publicaciones periódicas. Sin embargo, no podemos verla como un producto aislado de una persona, sino como parte de un proceso de producción social en el que van articulándose formulaciones preexistentes con estos nuevos discursos en torno a las responsabilidades y obligaciones adultas frente a los niños. De ahí su significación para avanzar en la historización de procesos que exceden la producción de una persona en particular y sus intenciones. Del mismo modo, es importante entender a esta obra en relación a su contexto de producción, en el que la difusión que comenzaron a tener las teorías "psi" se fue articulando con los cambios en los modos de vida familiar y de crianza (Cosse, 2006 y 2010b). Y tal como venimos planteando, estos discursos han dejado una impronta significativa en las formas contemporáneas en que se buscan regular las formas de vida familiar y las acciones adultas en torno a la educación infantil.

En efecto, la bibliografía especializada que analiza la EPP da cuenta de su influencia en el proceso de "psicologización" de la infancia. Y con ello, evidencia cómo se han complejizado las atribuciones consideradas necesarias a cargo de los padres y más aún de las madres, según hemos ido planteando a lo largo de este trabajo, junto con el desarrollo de nuestro análisis. Sin embargo, sostenemos que no sólo ha tenido estos efectos ya estudiados, sino que también ha dado lugar a un aumento de los requerimientos dirigidos a los padres respecto al desarrollo de la escolarización infantil. Por tanto, concluimos que este proceso constituye uno de los hitos que han llevado a que en la actualidad esta modalidad específica de concebir 
las responsabilidades y obligaciones adultas se haya consolidado como hegemónica, según se documenta en el amplio abanico de producciones mencionadas al principio. Con ello, sostenemos que la EPP puede ser leída como una producción significativa en el proceso de producción de la relación entre las familias y las escuelas como un "problema social". Como hemos analizado, esta obra da pie a ubicar en las acciones parentales, y las maternas especialmente, los problemas de los niños, en lo cual quedan potencialmente incluidas las explicaciones sobre el fracaso escolar infantil. Si comparamos estos nuevos requerimientos vinculados a la escolaridad con los previos - centrados en el cumplimiento de la obligatoriedad—, observamos cómo se va dando lugar a una reconfiguración en el modo en que se representa cómo debe ser la relación entre las familias y las escuelas, y qué responsabilidades serían competencia de unas y otras.

En este sentido, al alcanzar al ámbito educativo, estos discursos han encontrado un terreno fértil en el que desarrollarse de distintas formas (Plotkin, 2003; Carli, 1997). En sus orígenes, se trató de consejos de tono prescriptivo, apelaciones, indicaciones, relativamente novedosas en términos de las ideas que buscaban instalar, pero sin producir rupturas profundas con los paradigmas precedentes. Y luego, dada la gran permeabilidad que han tenido, se han ido transformando - no sin cambios, pero sí con llamativas similitudes- en condiciones sine qua non, en prescripciones y en supuestos profundamente anclados en las representaciones sociales actuales.

Vale insistir en que la permeabilidad que han tenido estos discursos no es lineal ni directa, está mediada por complejos procesos de apropiación y resistencia. Así, el objetivo específico de este artículo se centró en ubicar algunos aspectos significativos de esta obra para entender cómo se ha ido configurando un campo de regulaciones y representaciones sobre el deber ser de las familias de los niños, con especial énfasis en las mujeres. En relación a nuestro proceso de investigación previo y de los interrogantes que nos formulamos, es sumamente sugestivo observar las afinidades entre lo analizado acá y lo que es actualmente sostenido con toda frecuencia por los docentes y otros agentes del sistema educativo. Y más aún, por los lineamientos de diversas políticas jurisdiccionales y de organismos internacionales, como hemos aludido. Desde ya, profundizar en las hipótesis que presentamos acá implica continuar desarrollando la indagación sistemática y en profundidad sobre los modos en que estos discursos han sido apropiados y resignificados. Está abierta en, este sentido, la búsqueda por dar cuenta con progresiva complejidad de las huellas que permiten entender las relaciones entre el presente y los procesos a través de los cuales se han ido desarrollando las configuraciones contemporáneas que estudiamos.

\section{Referencias bibliográficas}

\section{ACHILLI, Elena.}

2005 Investigar en Antropología Social. Los desafios de transmitir un oficio. Rosario: Laborde Editor.

ALTHABE, Gérard; HERNÁNDEZ, Valeria.

2004 "Implication et réflexivité en anthropologie". Journal des anthropologues, 98-99: 15-36. Disponible en: http://jda.revues.org/1633 
ANDERSON, Kellie; MINKE, Kathleen.

2007 "Parent involvement in education: toward an understanding of parents' decision making". Journal of Educational Research, vol. 100, núm. 5: 311-323.

BOURDIEU, Pierre; WACQUANT, Loïc.

1998 "Una duda radical", en P. Bourdieu, L. Wacquant, Respuestas. Por una Antropología Reflexiva. México: Grijalbo, 177-184.

CARLI, Sandra.

1997 "Infancia, psicoanálisis y crisis de generaciones. Una exploración de las nuevas formas del debate en educación", en A. Puiggrós (Dir.), Dictadura y Utopías en la historia reciente de la educación argentina (1955-1983). Buenos Aires: Galerna, 221-287.

2005 Niñez, pedagogía y política. Transformaciones de los discursos acerca de la infancia en la historia de la educación argentina entre 1880 y 1955. Buenos Aires: Miño y Dávila.

CERLETTI, Laura.

2010 “Uno piensa que lo maternal está...': sobre las “madres” y la escolarización infantil”, en MR. Neufeld, L. Sinisi, J.A. Thisted (Eds.), Docentes, padres y estudiantes en épocas de transformación social. Investigaciones etnográficas en contextos de desigualdad y diversidad sociocultural. Buenos Aires: Editorial de la Facultad de Filosofía y Letras. Universidad de Buenos Aires, 133-153.

2014 Familias y escuelas. Tramas de una relación compleja. Buenos Aires: Biblos.

COSSE, Isabella.

2006 "Cultura y Sexualidad en la Argentina de los sesenta: usos y resignificaciones de la experiencia transnacional". Revista Estudios Interdisciplinarios de América Latina y el Caribe, vol. 17, núm. 1: 39-53. Disponible en: http://www1.tau.ac.il/ eial/index2.php?option $=$ com_content\&do_pdf $=1 \& i d=70$

2008 "Progenitores y adolescentes en la encrucijada de los cambios de los años sesenta. La mirada de Eva Giberti”. Revista Escuela de Historia, 7: 233-247. Disponible en: http://www.scielo.org.ar/scielo.php?script=sci_arttext\&pid= S1669-90412008000200004\&lng=es\&nrm=iso

2010a Pareja, sexualidad y familia en los años sesenta. Buenos Aires: Siglo XXI.

2010b "Argentine Mothers and Fathers and the New Psychological Paradigm of ChildRearing (1958-1973)”. Journal of Family History, vol. 35, núm. 2: 180-202. doi: http://dx.doi.org/10.1177/0363199010363352

DARRÉ, Silvana.

2013 Maternidad y tecnologías de género. Buenos Aires: Katz.

DONZELOT, Jacques.

1991 La policía de las familias. Madrid: Alianza.

EZPELETA, Justa; ROCKWELL, Elsie.

1987 La escuela, relato de un proceso de construcción inconcluso. Centro de Investigación y de Estudios Avanzados del Instituto Politécnico Nacional, México. 
FINOCCHIO, Silvia.

2009 La escuela en la historia argentina. Buenos Aires: Edhasa.

GIBERTI, Eva.

1968 [1961] Escuela para Padres. Buenos Aires: Esece.

2005 La familia, a pesar de todo. Buenos Aires: Noveduc.

s/f La experiencia de Escuela para Padres. Disponible en: www.evagiberti.com.

HURTIG, Janise; DYRNESS, Andrea.

2011 "Parents as critical Educators and Ethnographers of schooling", en B. Levinson, M. Pollock (Eds.), A Companion to the Anthropology of Education. EEUU: Blackwell Publishing Ltd., 531-546.

MARTIÑÁ, Rolando.

2003 Escuela y familia: una alianza necesaria. Buenos Aires: Troquel.

MORGADE, Graciela.

1992 El determinante de género en el trabajo docente de la escuela primaria. Buenos Aires: Miño y Dávila/IICE.

NARI, Marcela.

2004 Políticas de maternidad y maternalismo politico. Buenos Aires, 1890-1940. Buenos Aires: Biblos.

NEUFELD, María Rosa.

1996/1997 “Acerca de Antropología Social e Historia: una mirada desde la Antropología de la Educación". Cuadernos Del Instituto Nacional de Antropología y Pensamiento Latinoamericano, 17: 145-158.

NOGUEIRA, Maria Alice.

2011 "A categoria "família" na pesquisa em sociologia da educação: notas preliminares sobre um processo de desenvolvimento". Revista Inter-legere, 9: 156-166. Disponible en: http://www.cchla.ufrn.br/interlegere/09/pdf/09es09.pdf

OHAYON, Annick.

2000 "L'éducation des parents: histoire d'une illusion". La Lettre du Grape, 41: 83-91. Disponible en: http://www.cemea.asso.fr

PLOTKIN, Mariano.

2003 Freud en las pampas. Orígenes y desarrollo de una cultura psicoanalítica en la Argentina (1910-1983). Buenos Aires: Sudamericana.

PUIGGRÓS, Adriana (Dir.).

1991 Sociedad civil y Estado en los orígenes del sistema educativo argentino. Historia de la Educación Argentina II. Buenos Aires: Galerna.

ROCKWELL, Elsie.

2009 La Experiencia Etnográfica. Historia y cultura en los proceso educativos. Buenos Aires: Paidós. 
2011 "Los niños en los intersticios de la cotidianeidad escolar. ¿Resistencia, apropiación o subversión?”, en G. Batallán y M.R. Neufeld (Coords.), Discusiones sobre infancia y adolescencia. Niños y jóvenes dentro y fuera de la escuela. Buenos Aires: Biblos, 27-51.

RODRÍGUEZ DE ANCA, Alejandra.

2004 "Apuntes para el análisis de las relaciones entre discurso médico y educación (1900-1930)", en M.S. Di Liscia y G. N. Salto (Eds.), Higienismo, educación y discurso en la Argentina (1870-1940). Santa Rosa: Editorial de la Universidad Nacional de La Pampa, 15-35.

RUSTOYBURU, Cecilia.

2010 "Entre reflexivas y madres patógenas. Las mujeres en los discursos de la Escuela para Padres en los años 1960”, en N. Álvarez (Comp.), Familias, género y después... Itinerarios entre lo público, lo privado y lo íntimo. Rosario: Prohistoria, 53-78.

SANJEK, Roger.

1991 “The ethnographic present”. Man, vol. 26, núm. 4: 609-628. Disponible en: http:// www.jstor.org/stable/2803772

SANTILLÁN, Laura.

2009 "De responsabilidades y demandas que cambian". Revista Novedades Educativas 222: 14-17.

2012 Quiénes educan a los chicos. Infancia, trayectorias educativas y desigualdad. Buenos Aires: Biblos.

SANTILLÁN, Laura; CERLETTI, Laura.

2011 "Familias y escuelas: repensando la relación desde el campo de la Antropología y la Educación”. Boletín de Antropología y Educación, 3: 7-16. Disponible en: http:// ica.institutos.filo.uba.ar/seanso/pae/boletin/numeros/n03/bae_n03.html.

SEGALEN, Martine.

1992 Antropología histórica de la familia. Madrid: Taurus.

VELASCO, Honorio; DÍAZ DE RADA, Ángel

1997 La lógica de la investigación etnográfica. Un modelo de trabajo para etnógrafos en la escuela. Madrid: Ed. Trotta.

VEZZETTI, Hugo.

1999 "Las promesas del psicoanálisis en la cultura de masas", en F. Devoto, M. Madero (Coords.), Historia de la vida privada en la Argentina 3. La Argentina entre multitudes y soledades. De los años treinta a la actualidad. Buenos Aires: Taurus, 173-198. 